
\title{
25 Research Square \\ Experimental study on ultrasonic vibration-assisted grinding of hardened steel using white corundum wheel
}

Qiang Huang

Biao Zhao ( $\nabla$ zhaobiao@nuaa.edu.cn )

Nanjing University of Aeronautics and Astronautics https://orcid.org/0000-0002-8625-3935

Yang Cao

Wenfeng Ding

Yucan Fu

Changlan Pu

Menglan Tang

Mingming Deng

Guoliang Liu

\section{Research Article}

Keywords: Grinding temperature, Grinding specific energy, Coolant heat transfer coefficient, Ultrasonic vibration-assisted grinding, Hardened steel

Posted Date: February 11th, 2022

DOI: https://doi.org/10.21203/rs.3.rs-1342898/v1

License: (c) (1) This work is licensed under a Creative Commons Attribution 4.0 International License.

Read Full License 


\section{Abstract}

Ultrasonic vibration assisted grinding (UVAG) combined with the ultrasonic vibrating method and CG process was proposed, aiming at improving the grindability of hardened steel in conventional grinding (CG) process. Comparative investigations on grinding force, temperature, and specific grinding energy for both grinding processes were studied in detail. In addition, the morphologies of wheel wear surface and ground surface were also conducted. Findings show that in comparison of CG processes, the grinding forces in UVAG are reduced greatly by $16.44 \%$ and $17.44 \%$, for normal and tangential forces, respectively. The UVAG process attributes to a lower specific grinding energy by $8.30 \%$ owing to the increase of maximum undeformed chip thickness, and a smaller grinding temperature by $19.01 \%$ due to the improvement of coolant heat transfer capacity in the grinding arc zone. Meanwhile, the promising grain sharpness of wheels can be guaranteed, resulting from the enhanced cooling function on grinding arc zone and grains micro-fracture caused by ultrasonic impacting actions.

\section{Introduction}

Hardened steel has been widely used in the automotive and aerospace industries including automotive crankshafts, cutting tools, bearings and molds, owing to its superior mechanical properties and high wear-resistances $[1,2]$. Here, the existence of high-carbon martensite inside heat treatment layers of hardened steels attributes to the whole poor machinability and low thermal conductivity $[3,4]$. Grinding processes as an important method were employed to eliminate deformation after heat treatment and improve the accuracy of the workpiece. However, the unexpected grinding burn easily occurs due to the aggregation of high grinding force and heat on the workpiece surface, resulting in poor surface quality and high surface residual tensile stress [5-7]. In this case, a new machining technology is urgently needed to reduce the grinding force and heat.

Ultrasonic vibration-assisted grinding (UVAG) technique as an excellent method has been earned increasing attention to significantly improve the grindability of difficult-to-cut materials domestic and overseas [8, 9]. Cao et al. [10] performed the comparative study using CG and UVAG processes on nickelbased superalloy, and revealed that the tangential and normal grinding forces decreased by $30 \%$ and $40 \%$, respectively, due to the acoustic softening and ultrasonic friction reduction effects. Dai et al. [11] reported that the peening effect of abrasive ultrasonic vibration would raise brittle fracture and soften the workpiece surface during grinding $\mathrm{SiC}$ ceramic material, resulting in the significant reduction of normal force, tangential force and radial force by $69 \%, 52 \%$ and $71 \%$, respectively. Zhang et al. [12] presented that the average undeformed chip thickness could be reduced during machining brittle removal of $\mathrm{C}_{f} / \mathrm{SiC}$ composites via UVAG processes due to the interference of the abrasive trajectory brings intermittent noncutting processes. Here, the normal force and tangential force were thus decreased by $20.44 \%$ and 17.66 , respectively. Along this line of consideration, the employment of ultrasonic vibrating methods on traditional machining processes attributes to reduce grinding forces and temperature, and thus improve machining surface integrity and tools wear-resistance ability, eventually. However, the researches on 
hardened steel materials have yet to be fully investigated about the material removal characteristics and grinding heat transfer mechanism under UVAG processes.

Furthermore, the sudden grinding burn usually occurs due to the accumulation of grinding heat on machining surface, which has a devastating influence on the blockage of grinding wheels, and associated ground surface quality $[13,14]$. In recent decades, numerous researchers have always focused their attentions on controlling the generation [15], and conduction [16] of grinding heat. Malkin et al. [17] studied that the grinding temperature could be availably reduced by controlling the grinding specific energy. Here, a reduction in grinding specific energy ranged from $105 \mathrm{~J} / \mathrm{mm}^{3}$ to $70 \mathrm{~J} / \mathrm{mm}^{3}$, resulting in a $33 \%$ reduction in grinding temperature. Single et al. [18] conducted the theoretical modeling and experimental research on the different components of specific grinding energy, including the energy of chip formation, primary and secondary rubbing and ploughing, contributing to predict the specific grinding energy. Subsequently, Jeager et al. [19] proposed a one-dimensional moving heat source model to connect the heat flow into the workpiece with the internal temperature field, providing a theoretical basis for grinding thermal analysis. Based on the model established by Jaeger et al. [19], Rowe et al [20] analyzed the four conduction modes of the total grinding heat and the theoretical model of heat distribution, clarifying the influence of the material physical parameters and the grinding parameters on grinding temperature. Lavisse et al. [21] conducted the high-flow and high-speed jet grinding experiments, which greatly reduced the grinding heat absorbed by workpieces, resulting in a $50 \%$ reduction in heat distribution ratio and maximum temperature in grinding arc zone. Therefore, the grinding thermal analysis is needed to further performed, controlling the grinding temperature during CG and UVAG processes.

In this paper, the comparative experiments were conducted to study the effect of ultrasonic vibration and grinding parameters on the grindability of hardened steel under CG and UVAG processes. After showing the introduction part, the experimental setup and associated equipment were displayed in section 2 . Subsequently, section 3 reveals the influence of ultrasonic vibration processes and grinding parameters on grinding force, grinding specific energy, coolant heat transfer coefficient, grinding surface temperature, wheel wear, and grinding surface defects. Finally, the corresponding conclusion is summarized in the last section.

\section{Experiment Environment \\ 2.1 Experimental setup}

In this trial, grinding operations were conducted on surface grinder (Blohm Profimat MT-408), and white corundum grinding wheels (WA80F13V45m) was used. Here, the corresponding experiment setup and grinding device are shown in Fig. 1. As seen from the left part of Fig. 1, ultrasonic vibration platform system was used and then the ultrasonic generator generates high-frequency vibration signal [10]. Subsequently, the tangential vibration is generated in the center area of the platform by amplifying the amplitude of the horn. In this paper, GCr15 hardened steel was applied as workpiece materials (HRC 62) 
with dimensions of $30 \mathrm{~mm} \times 10 \mathrm{~mm} \times 12 \mathrm{~mm}(\mathrm{~L} \times \mathrm{W} \times \mathrm{H})$. The material composition of GCr15 hardened steel is listed in Table 1. In addition, Table 2 shows some typical values of thermal performance of workpiece and grinding wheel materials used for the further investigation of coolant heat transfer coefficient during grinding processes. Furthermore, a sealed shell was adopted to keep the UVAG system running stably under the coolant, and then continuous injection of air cooling is used to keep the proper working temperature inside the transducer.

Table 1

Material components of GCr15 hardened steel (\%)

\begin{tabular}{|llllllllll|}
\hline Material & $\mathbf{C}$ & $\mathbf{S i}$ & $\mathrm{Mn}$ & $\mathbf{P}$ & $\mathbf{S}$ & $\mathrm{Cr}$ & $\mathrm{Ni}$ & $\mathrm{Mo}$ & $\mathrm{Fe}$ \\
\hline GCr15 & 1.03 & 0.227 & 0.353 & 0.007 & 0.003 & 1.46 & 0.015 & 0.0096 & Balance \\
\hline
\end{tabular}

Table 2

Thermal properties of aluminum oxide and GCr15 hardened steel

\begin{tabular}{|lllll|}
\hline Material & $\begin{array}{l}\text { Conductivity } k \\
(\mathrm{~W} / \mathrm{mK})\end{array}$ & $\begin{array}{l}\text { Density } \rho \\
\left(\mathrm{kg} / \mathrm{m}^{3}\right)\end{array}$ & $\begin{array}{l}\text { Specific heat } c \\
(\mathrm{~J} / \mathrm{kgK})\end{array}$ & $\begin{array}{l}\text { Thermal property } \\
\left(\mathrm{J} / \mathrm{m}^{2} \mathbf{s K}\right)\end{array}$ \\
\hline GCr15 & 34.3 & 7815 & 506 & 11650 \\
\hline Aluminum oxide & 35.0 & 3980 & 765 & 10300 \\
\hline
\end{tabular}

Prior to the grinding operation, the vibration frequency and amplitude of the workpiece without loads were calibrated. Here, three uniform points on the end face of the workpiece were selected, and laser doppler vibrometer was used to measure the amplitude. After real-time FFT analysis of the Quick SA software of the personal computer, the workpiece can produce stable ultrasonic amplitude of $4 \mu \mathrm{m}$ when the ultrasonic generator power is $19 \%$ and the vibration frequency is $19.70 \mathrm{kHz}$. Subsequently, the set of UVAG system is fixed on the grinder platform through the platen. During experiment, surface grinding was carried out 5 times using the parameters in Table 3 , and the grinding force and temperature were recorded. Water-based coolant containing $5 \%$ emulsion were used. After the experiment, in order to eliminate the influence of the wear of the grinding wheel and the difference of surface quality after multiple grinding, uniform grinding parameters are used to dress the surface of the workpiece (Grinding speed of $v_{\mathrm{s}}=25 \mathrm{~m} / \mathrm{s}$, workpiece speed of $v_{\mathrm{w}}=7.5 \mathrm{~m} / \mathrm{min}$, the depth of cut $a_{\mathrm{p}}=15 \mu \mathrm{m}$ ), then dressing diamond is used to trim the grinding wheel to keep the ability of cutting materials, the trimming parameters are $v_{\mathrm{st}}=20 \mathrm{~m} / \mathrm{s}, v_{\mathrm{wt}}=200 \mathrm{~mm} / \mathrm{s}, a_{\mathrm{pt}}=100 \mu \mathrm{m}$.

Table 3 Grinding process parameters for both grinding processes. 


\begin{tabular}{ll}
\hline Contents & Values \\
\hline Machine tool & Surface Grinder Blohm Profimat MT-408 \\
Grinding mode & Surface down grinding \\
Abrasive wheel & White alundum wheel (WA/80F13V45m) \\
Grinding speed $v_{\mathrm{s}}$ & $15-30 \mathrm{~m} / \mathrm{s}$ \\
Workpiece speed $v_{\mathrm{w}}$ & $4.5-9 \mathrm{~m} / \mathrm{min}$ \\
Depth of cut $a_{\mathrm{p}}$ & $10-25 \mu \mathrm{m}$ \\
Grinding width $b$ & $10 \mathrm{~mm}$ \\
Cooling condition & $5 \% \mathrm{emulsified} \mathrm{water;} \mathrm{pressure} \mathrm{at} 0.2 \mathrm{MPa}$ \\
\hline
\end{tabular}

During this comparative experiment, the four-phase piezoelectric dynamometer (i.e. Kistler 9253B) and multi-channel charge amplifier (Kistler 5080A) were employed to measuring grinding forces. In addition, the semi-artificial thermocouple was applied to obtain thermoelectric signals recorded by NI USB-6211 DAQ card and processed by NI-LabView software, and then the grinding temperature could be calculated using the relationship between the actual temperature $(T)$ and thermoelectric value $(E)$. Here, this relationship was achieved via the standard calibration method, and then this relationship could be expressed as follows [22]:

$T=-0.0223 E^{2}+18.2532 E-6.0770(1)$

After grinding processes, the machined workpiece should be dealt with $75 \%$ alcohol by ultrasonic cleaning methods. Meanwhile, after grinding experiments, the abrasive layer of grinding wheels for both CG and UVAG processes was broken up into small pieces, and then these pieces should be cleaned throughout under same cleaning methods, aiming at revealing the influence of grinding processes on the wheel wear. Subsequently, these pieces of wheels were detected by a scanning electron microscope (Quanta 200).

\section{Results And Discussion 3.1 Grinding forces}

Grinding forces as an important indicator has a great influence on the grinding specific energy, grinding temperature, grinding wheel performance, and ground surface quality [23]. Fig. 2 shows the influence of grinding parameters on the normal force $F_{\mathrm{n}}$ and tangential force $F_{\mathrm{t}}$ during $\mathrm{CG}$ and UVAG processes. When grinding speed $v_{\mathrm{s}}$ rises from 15 to $30 \mathrm{~m} / \mathrm{s}$, the normal force of CG decreases from $103.95 \mathrm{~N}$ to $63.91 \mathrm{~N}$, tangential force of CG decreases from $46.17 \mathrm{~N}$ to $29.45 \mathrm{~N}$ as illustrated in Fig. 2a. A similar varying 
tendency with the $F_{\mathrm{n}}$ and $F_{\mathrm{t}}$ can be observed in UVAG process compared to the other one, while as the normal and tangential forces are always lower than the other one by $2.69 \%-6.98 \%$ and $4.87 \%-7.91 \%$, respectively. However, the difference is small with the change of grinding speed, indicating that grinding speed had little significant effect on the ability of UVAG in terms of the reduction of grinding forces. In addition, the $F_{\mathrm{n}}, F_{\mathrm{t}}$ of CG/UVAG rises with the increases of workpiece speed $v_{\mathrm{w}}$ (Fig. 2b). Meanwhile, the maximum difference between UVAG and CG normal force and tangential force occurs at the maximum feed speed $v_{\mathrm{w}}$ of $9 \mathrm{~m} / \mathrm{min}$, which are $8.94 \%$ and $12.19 \%$ respectively. Due to the increase of workpiece feed speed, the intermittent grinding phenomenon between the abrasive particles and workpiece is more likely to occur. As illustrated in Fig. 2c, the $F_{\mathrm{n}}, F_{\mathrm{t}}$ of CG and UVAG increase with the rise of depth of cut $a_{\mathrm{p}}$. However, the difference of $F_{\mathrm{n}}, F_{\mathrm{t}}$ between UVAG and CG is most obvious at the smaller cutting depth $\left(a_{\mathrm{p}}=10 \mu \mathrm{m}\right)$, and decreases by $16.44 \%$ and $17.44 \%$, respectively, indicating that the UVAG process with soft WA wheel is suitable for the smaller cutting depth. As for the large cutting depth, there is little difference between grinding forces for UVAG and CG processes. The main reason can be summarized that although ultrasonic vibration improve the ability of self-sharpening effect for grains [24] and it will accelerate wheel wear under a large depth of cut, so that the grinding force of UVAG and CG is similar at a large depth of cut.

\subsection{Specific grinding energy}

Specific grinding energy $e_{\mathrm{s}}$ as an important indicator to evaluate the degree of difficulty in removing materials and measure the generated heat during grinding processes, presents the consumed energy by removal materials per volume, which can be expressed as follows:

$$
e_{\mathrm{s}}=\frac{P}{v_{\mathrm{w}} a_{\mathrm{p}} b}=\frac{F_{\mathrm{t}} v_{\mathrm{s}}}{v_{\mathrm{w}} a_{\mathrm{p}} b}
$$

Where the grinding width $b$ of workpiece is fixed at $10 \mathrm{~mm}$.

In order to investigate the specific grinding energy clearly, the maximum undeformed chip thickness should be studied [25]. Here, as mentioned by Pahlitzsch et al [26], the maximum undeformed chip thickness $a_{\text {gmax }}$ can be given using the following expression (Eq. 3) in consideration of the adjacent abrasive grains with the same spacing of grinding wheels.

$$
a_{g \max }=2 \frac{\lambda_{\mathrm{s}} v_{\mathrm{w}}}{v_{\mathrm{s}}} \sqrt{\frac{a_{\mathrm{p}}}{d_{\mathrm{s}}}}
$$

Seen from Fig. 3 , the evolution of specific grinding energy $e_{s}$ affected by the grinding wheel speed, feed speed, depth of cut was plotted, respectively. As the grinding speed $v_{\mathrm{s}}$ increases from 15 to $30 \mathrm{~m} / \mathrm{s}$ under the feed speed $v_{\mathrm{w}}$ of $7.5 \mathrm{~m} / \mathrm{min}$ and cutting depth $a_{\mathrm{p}}$ of $15 \mu \mathrm{m}$, the specific grinding energy $e_{\mathrm{s}}$ of CG increases from $36.94 \mathrm{~J} / \mathrm{mm}^{3}$ to $47.12 \mathrm{~J} / \mathrm{mm}^{3}$, by $27.56 \%$ and UVAG increases from $35.14 \mathrm{~J} / \mathrm{mm}^{3}$ to 
$43.39 \mathrm{~J} / \mathrm{mm}^{3}$, by $23.48 \%$, respectively (Fig. 3a). Seen from Fig. $3 \mathrm{~b}$, as the $v_{\mathrm{w}}$ value increases from 4.5 $\mathrm{m} / \mathrm{min}$ to $9 \mathrm{~m} / \mathrm{min}$ with the $v_{\mathrm{s}}$ of $25 \mathrm{~m} / \mathrm{s}$ and $a_{\mathrm{p}}$ of $15 \mu \mathrm{m}$, the $e_{\mathrm{s}}$ value of CG decreases from 49.22 $\mathrm{J} / \mathrm{mm}^{3}$ to $40.56 \mathrm{~J} / \mathrm{mm}^{3}$, by $17.59 \%$ and UVAG decreases $45.58 \mathrm{~J} / \mathrm{mm}^{3}$ to $35.61 \mathrm{~J} / \mathrm{mm}^{3}$, by $21.87 \%$, respectively. As $a_{\mathrm{p}}$ increases from 10 to $25 \mu \mathrm{m}$, the $e_{\mathrm{s}}$ value of $\mathrm{CG}$ decreases by $35.68 \%$ from 55.04 $\mathrm{J} / \mathrm{mm}^{3}$ to $35.40 \mathrm{~J} / \mathrm{mm}^{3}$, and UVAG decreases by $24.14 \%$ from $45.44 \mathrm{~J} / \mathrm{mm}^{3}$ to $34.47 \mathrm{~J} / \mathrm{mm}^{3}$, respectively (Fig. 3c). Fig. 3d demonstrates the $e_{\mathrm{s}}$ decreases with the rise of $a_{\text {gmax }}$ according to Eq. 3. It can be found that the $e_{\mathrm{S}}$ of UVAG fitting curves is reduced in range of $5.30 \%-11.29 \%$ compared with CG. Meanwhile, the decreasing tendency of $e_{\mathrm{s}}$ with the increase of $a_{\text {gmax }}$ reveals that UVAG has better grindability than CG, lower grinding energy consumption and grinding heat generation. This phenomenon can be explained in view of different material removal stages (e.g. scratching, ploughing and cutting) of abrasive grains. There are more consumed energy in scratching and ploughing due to the size effect according to Eq. 3 . Here, the $a_{g \text { max }}$ is increased with the decrease of $v_{\mathrm{s}}$ and rise of $v_{\mathrm{w}}$ and $a_{\mathrm{p}}$, which reflected in the reduction of $e_{\mathrm{s}}$.

Aim at investigate the influence of ultrasonic vibration parameters on material cutting processes clearly, the $a_{\text {gmax }}$ model of UVAG methods was established in basis of traditional grinding processes, which was illustrated in Fig. 4. Here, the $a_{\text {gmax }}$ value (Eq. 4) could be rewritten using the line of EH.

$$
a_{\text {gmax }}=E H=E F \cdot \sin \theta
$$

4

According to the coordinate system in Fig. 4, the moving trajectory of two continuous abrasive grains with a distance of $\lambda_{\mathrm{s}}$ during UVAG processes could be expressed as follows:

$$
\left\{\begin{array}{l}
x_{u, i}=v_{\mathrm{w}} t+A \sin (\omega t)+R \sin \left(\frac{v_{\mathrm{s}}}{R} t\right) \\
y_{u, i}=R-R \cos \left(\frac{v_{\mathrm{s}}}{R} t\right) \\
x_{u, i-1}=v_{w}\left(t+\frac{\lambda_{\mathrm{s}}}{v_{\mathrm{s}}}\right)+A \sin \left(\omega\left(t+\frac{\lambda_{\mathrm{s}}}{v_{\mathrm{s}}}\right)\right)+R \sin \left(\frac{v_{\mathrm{s}}}{R} t\right) \\
y_{u, i-1}=R-R \cos \left(\frac{v_{\mathrm{s}}}{R} t\right)
\end{array}\right.
$$

Where $A$ is ultrasonic amplitude, $f$ is ultrasonic frequency, $t$ is current time, $R$ is the radius of grinding wheel. Seen from Eq. 5, the following equation could be presented:

$E F_{u}=x_{u, i-1}-x_{u, i}=\frac{\lambda_{s} V_{w}}{v_{s}}+A \sin \left(\omega\left(t+\frac{\lambda_{s}}{v_{s}}\right)\right)-A \sin (\omega t)$ 
In this case, the $a_{\text {gmax }}$ needed to be calculated within a period, that is, $t=-\lambda_{\mathrm{s}} /\left(2 v_{\mathrm{s}}\right)$. Here, the maximum value of $E F_{u}$ should be:

$E F_{u, \max }=\frac{\lambda_{s} v_{W}}{v_{s}}+2 A \sin \left(\omega \frac{\lambda_{s}}{2 v_{s}}\right)(7)$

$\sin \theta=\frac{\sqrt{d_{s}^{2}-\left(d_{s}-2 a_{p}\right)^{2}}}{d_{s}}=\frac{\sqrt{4 d_{s} a_{p}-4 a_{p}^{2}}}{d_{s}}$, after simplification: $\sin \theta=2 \sqrt{\frac{a_{p}}{d_{s}}}(8)$

Therefore, the maximum undeformed chip thickness $a_{\mathrm{u}, \mathrm{gmax}}$ of UVAG could be concluded as:

$a_{u, g \max }=2\left(\frac{\lambda_{s} V_{W}}{v_{s}}+2 A \sin \left(\frac{\omega \lambda_{s}}{2 v_{s}}\right)\right) \sqrt{\frac{a_{p}}{d_{s}}}(9)$

According this line of consideration based on Eq. 9, the maximum undeformed chip thickness $a_{\mathrm{u}, g m a x}$ was remarkably affected by the ultrasonic vibrating and grinding parameters. Moreover, the phenomenon of intermittent cutting processes between the abrasive grain and workpiece could be concluded in aspects of the $a_{\mathrm{u}, \mathrm{gmax}}$ model (see Eq. 9) and schematic diagram (see Fig. 4). Fig. 5 shows the relationship between the $a_{u, g m a x}$ and ultrasonic amplitude as well as specific grinding energy. The actual value of $a_{\mathrm{u}, \mathrm{gmax}}$ of UVAG is larger than that of $\mathrm{CG}$ and the entering speed of cutting stage of the former one is faster than the later one. Under the grinding parameters (e.g. grinding speed of $25 \mathrm{~m} / \mathrm{s}$, feed speed of 7.5 $\mathrm{m} / \mathrm{min}$, and cutting depth of $15 \mu \mathrm{m}$ ) as well as the ultrasonic amplitude of $4 \mu \mathrm{m}$, the $a_{\mathrm{u}, g \mathrm{max}}$ of UVAG increased by $25.4 \%$ compared with CG according to Eq. 9. Seen from fitting curves in Fig. 5b, a slight higher of the $e_{\mathrm{s}}$ value for UVAG than that of CG with the increase of $a_{\mathrm{u}, g m a x}$ value. This can be explained that the ability of the UVAG to reduce $e_{\mathrm{s}}$ decreases with the increase of $a_{u, g m a x}$, because the ultrasonic vibration process has a more obvious effect on the smaller $a_{u, g m a x}$ value.

\subsection{Grinding temperature and coolant heat transfer coefficient}

During grinding processes, amount of energy was required to remove materials and then most of those energy would be converted into heat. Here, the heat would be transmitted into the workpiece surface, resulting in grinding burns and affecting the service life of workpiece eventually [27]. Fig. 6 illustrates the relationship between grinding temperatures and grinding parameters for both grinding methods. As the grinding wheel speed rise from 15 to $30 \mathrm{~m} / \mathrm{s}$, the grinding temperature of $C G$ rise from $87.80^{\circ} \mathrm{C}$ to $100.68^{\circ} \mathrm{C}$, and the grinding temperature of UVAG increases from $77.22^{\circ} \mathrm{C}$ to $90.25^{\circ} \mathrm{C}$. Here, the grinding temperature of UVAG is generally lower than that of $C G$, with a decrease of $10.36-12.48 \%$. The grinding temperature rises with the rise of feed speed $v_{w}$, as seen from Fig. $6 \mathrm{~b}$. The tendency of grinding temperature of UVAG and CG was similar, but the temperature of UVAG decreased by $10.82 \%-19.01 \%$ 
compared with CG. In addition, the grinding temperature of CG and UVAG increases with the rise of $a_{\mathrm{p}}$ (see Fig. $6 \mathrm{c}$ ), and the grinding temperature of UVAG is always lower than CG, ranging from $5.84 \%-17.45 \%$. This phenomenon reveals that the grinding temperature can be effective reduced by employing ultrasonic vibrating techniques into traditional grinding processes, owing to the smaller $e_{\mathrm{s}}$ value under the same $a_{\mathrm{u}, \mathrm{gmax}}$

During grinding processes, the total grinding heat flux $\left(q_{\mathrm{t}}\right)$ was transmitted into various parts, including workpiece $\left(q_{\mathrm{w}}\right)$, grinding wheel $\left(q_{\mathrm{s}}\right)$, chip $\left(q_{\mathrm{ch}}\right)$, and coolant $\left(q_{f}\right)$, respectively [15]. Here, the total heat flux is deduced as:

$q_{t}=q_{W}+q_{S}+q_{C h}+q_{f}$ where $q_{t}=\frac{F_{t} v_{s}}{b l_{c}}(10)(11)$

As an effective method to avoid grinding burns, the coolants heat transfer coefficient $h_{f}$ of can be expressed via the following formulas.

At first, in basis of the "fluid wheel" hypothesis, the thermal performance $\beta_{f}$ of coolants is considered and the coolant is not boiling [20]. In this case, the heat transfer coefficient can be written as:

$h_{f, \mathrm{FW}}=0.94 \beta_{f} \sqrt{\overline{I_{c}}}$

Then, when the coolant flowing through the grinding arc zone is regarded as a laminar outward sweep plate, the thermal conductivity and specific heat coefficient of water-based coolant are considered, based on the similarity principle of fluid mechanics [28]:

$h_{f, \mathrm{LW}}=0.759 \sqrt{\frac{V_{s}}{l_{c}}}(1$

Finally, the coolants heat transfer coefficient by backtracking the experimental data is confirmed, which is also the method adopted in this paper. Here, the convective heat transfer coefficient of coolant $h_{f, e x p}$ is presented as [29]:

$h_{f, \exp }=\frac{q_{\mathrm{t}}-h_{\mathrm{ch}} T_{\mathrm{ch}}}{T_{\max }-T_{0}}-\frac{h_{\mathrm{w}}}{R_{\mathrm{ws}}}=\frac{\frac{F_{\mathrm{t}} v_{\mathrm{s}}}{b l_{c}}-\rho_{\mathrm{w}} \cdot c_{\mathrm{w}} \cdot T_{\mathrm{ch}} \cdot \frac{a_{\mathrm{p}} v_{\mathrm{w}}}{l_{c}}}{T_{\max }-T_{0}}-\frac{\beta_{\mathrm{w}}}{C} \sqrt{\frac{v_{\mathrm{w}}}{l_{c}}} \cdot\left[1+\frac{0.97 k_{g}}{\beta_{\mathrm{w}} \sqrt{r_{g} v_{\mathrm{s}}}}\right]$, 
Where $I_{\mathrm{c}}$ is contact length, $\rho_{\mathrm{w}}$ is workpiece density, $c_{\mathrm{w}}$ is specific heat conductivity, $T_{\mathrm{ch}}$ is chip melting temperature, $\beta_{\mathrm{W}}$ is thermal performance of workpiece, $k_{\mathrm{g}}$ is thermal conductivity coefficient of abrasive particles, $\mathrm{C}$ is temperature factor, and $r_{g}$ is the effective contact radius of abrasive particles $(20 \mu \mathrm{m}$ in this article) [20].

Figure 7 shows the effect of grinding speed $v_{\mathrm{s}}$ and depth of cut $a_{\mathrm{p}}$ on coolant heat transfer coefficient according to Eq. 14. The coolant heat transfer coefficient increases with the rises of wheel speed and decreases of cutting depth, which shows the same rule as the "fluid wheel" model (see Eq. 12) and laminar flow model (see Eq. 13). Compared with the bar chart, suggesting the coolant heat transfer coefficient of UVAG is higher than CG, by $1.87 \%-11.2 \%$. Meanwhile, the strengthening effect of ultrasonic vibration on heat transfer coefficient is weakened as the grinding speed increases. Here, the reduction of grinding temperature caused by UVAG is that ultrasonic vibration improves the convective heat transfer capacity of coolant, leading to the reduction of heat flux allocated to the workpiece. Another important reason for the lower grinding temperature of UVAG shows that the ultrasonic vibration improves the convective heat transfer capacity of the coolant, leading to a decrease in heat flux allocated to the workpiece.

During grinding processes, the coolant in the grinding arc zone is normally regarded as the laminar fluid with the same grinding speed $[28,29]$, and its convective heat transfer capacity is usually measured with the thickness of the thermal boundary layer. Generally, the heat transfer coefficient with ultrasonic vibrating effects increases $20 \%-400 \%$ compared to traditional processes due to the strengthening effect on fluid heat transfer of vibrations. Here, the effect degree is depended on the vibration intensity and vibration system [30-32]. Fig. 8 illustrates the convection heat transfer mechanism of coolants under the influence of ultrasonic vibrations. The implosion of cavitation bubbles near the solid-liquid interface will destroy the thermal boundary layer and velocity boundary layer due to the cavitation or acoustic flow under low-frequency ultrasonic vibration of $20-100 \mathrm{kHz}$, reducing the thermal resistance and producing micro-turbulence. Meanwhile, the wall of workpiece vibration will disturb the laminar coolant flow boundary layer near the grinding arc surface and then increase the turbulence intensity. In this case, the fluid thermal boundary layer thickness in the grinding arc zone becomes thinner and the heat transfer capacity of the coolant in the grinding arc zone is thus enhanced. However, the strengthening effect of vibration is not obvious under a higher grinding speed due to the thinner wall of thermal boundary layer and greater ability of heat transfer, resulting from the larger flow Reynolds number and turbulence of the coolant. This reveals that the ability of ultrasonic cooling fluid heat transfer will decreases as the grinding speed raises. Besides, Fig. 4 and Eq. 5 show that "cutting- separating" phenomenon exists during the removal process of abrasive grains. At the separating stage, the gap between grinding wheel and workpiece increases, and thus the coolant flows into the sliding surface between the grain and workpiece, contributing to the heat dissipation of the contacting interface.

\subsection{Wear surface topography}


Figure 9 describes the typical SEM morphology and associated schematic images of the wheel wear surface under CG and UVAG processes, aiming at revealing the effect of ultrasonic vibrating process on wear behaviors of grinding wheels. Seen from the Figs. $9 a$ and $9 b$, the material adhesion can be clearly observed under CG processes, and the top surface of the abrasive grains is adhered with the cloud-like grinding material. Here, the chip and adhesive are mixed together. As illustrated in Fig. 9c, the long chips generated during CG processes are more difficult to remove from the wheel-workpiece interface than the shorter chips. In addition, the cutting point temperature of abrasive particles is much higher than the average grinding temperature during removing materials [33]. In this case, the adhesion of chips is easy to observed on the top of abrasive grains under the action of thermal and mechanical. On the other hand, when the ultrasonic vibration is applied in grinding processes, no adhesion wear is found on the top of abrasive grains. However, the grain micro-fracture can be observed, as shown in Figs. 9c and 9d. As depicted in Fig. 9f, the short chips are easier be produced and escaped from the grinding zone due to the "intermittent cutting" of abrasive particles. Meanwhile, the coolant can enter and cool the machined surface during the separation period for UVAG, and the cutting point temperature of abrasive particles is much lower than that of CG, consequently. Moreover, the multiple cutting edges on the top of abrasive grains are prone to produced owing to the influence of alternating loads, which can effectively keep the sharpness of the abrasive grain and thus reduce the grinding temperature.

\subsection{Ground surface topography}

Figure 10 shows the typical ground surface topography detected by SEM for both grinding processes under the grinding condition: $v_{\mathrm{s}}=25 \mathrm{~m} / \mathrm{s}, v_{\mathrm{w}}=7.5 \mathrm{~m} / \mathrm{min}, a_{\mathrm{p}}=25 \mu \mathrm{m}$. As illustrated in Figs. 10a and 10b, there are many surface defects for CG processes under the influence of mechanical and thermal actions, such as scratches, fracture, smearing, and redeposited materials. However, none of these surface defects can be observed on the surface after UVAG processes in Figs. 10c and 10d. Moreover, there are obvious traces of side flow, ploughing, and striation on the surfaces of UVAG. Because of the squeezing action between abrasive grains and workpiece, the long chip and large broken grain appear easily, and thus attributes to the formation of grinding scratches, fracture, and redeposited material on the surface of CG. However, the grinding temperature of UVAG is lower, the adhesion and diffusion wear are slight, and the abrasive particles are prone to form micro-fractures under ultrasonic impacts of workpiece [24]. Therefore, the grinding sharpness of abrasive grains for UVAG processes can be remained stable for a long term and thus the ground surface quality is greater than that of CG processes owing to the fewer grinding surface defects. In addition, the multiple micro ploughing and scratches can be produced due to the axial movement of the workpiece under multi-mode vibration, attributing to reduce the accumulation of removed materials and thus improve the grinding quality [34].

\section{Conclusions}

In this work, the comparative trials on the grindability of hardened GCr15 steel are conducted by the white alundum wheels under CG and UVAG processes. The influences of grinding parameters and ultrasonic vibrating parameters on grinding forces, grinding specific energy, coolant convection heat transfer

Page $11 / 22$ 
coefficient, grinding temperature, wheel wear, and ground surface quality are discussed exhaustively. The main conclusions are summarized as follows:

1. The UVAG process has the lower grinding forces by $2.69-16.44 \%$ for the normal force and $4.87-$ $17.44 \%$ for the tangential force in comparison of CG, owing to the larger undeformed chip thickness by applying ultrasonic vibrating methods to grinding processes.

2. Compared to CG processes, a smaller grinding temperature by $19.01 \%$ and specific grinding energy by $11.29 \%$ can be detected, resulting from the better cooling fluid convection heat transfer capacity and the reduction of thermal resistance as employing the ultrasonic vibration, respectively.

3. Multiple cutting edges of abrasive grains are produced because of the alternating load on the top of grains for UVAG processes, attributing to remain the wheel sharpness state and improve the ground surface quality eventually.

\section{Declarations}

Funding This work was financially supported by the National Natural Science Foundation of China (Nos. 51921003, 92160301 and 52175415), Natural Science Foundation of Jiangsu Province (No. BK20210295), and the Foundation of Graduate Innovation Centre in NUAA (No. XCXJH20210503)

Competing interests The authors have no conflicts of interest to declare that they are relevant to the content of this article.

Availability of data and material All data generated or analyzed during this study are included in the present article.

Authors' contributions Qiang Huang: experimentation, data curation, and writing the original draft. Biao Zhao: data collection and manuscript revision. Yang Cao: experimentation and methodology. Wenfeng Ding: supervision, conceptualization, and methodology. Yucan Fu: resources. Changlan Pu: funding acquisition. Menglan Tang: funding acquisition. Mingming Deng: funding acquisition. Guoliang Liu: funding acquisition.

Ethics approval and consent to participate The article follows the guidelines of the Committee on Publication Ethics (COPE) and involves no studies on human or animal subjects.

Consent to participate Not applicable.

Consent for publication Not applicable.

\section{References}

1. Sales WF, Schoop J, Silva LRR, Machado AR, Jawahir IS (2020) A review of surface integrity in machining of hardened steels. J Manuf Process 58:136-162 
2. Wu SX, Liu GD, Zhang WF, Chen WL, Wang CY (2022) Formation mechanism of white layer in the high-speed cutting of hardened steel under cryogenic liquid nitrogen cooling. J Mater Process Technol 302:117469

3. Davis JR (1998) Metals Handbook Desk Edition (second Edition). ASM International

4. Zhao HY, Huang RR, Sun YM, Tan CW, Wu LJ, Chen B, Song XG, Li GX (2020) Microstructure and mechanical properties of fiber laser welded QP980/press-hardened 22MnB5 steel joint. J Mater Res Technol 9:10079-10090

5. Trob N, Brimmers J, Bergs T (2021) Tool wear in dry gear hobbing of 20MnCr5 case-hardening steel, 42CrMo4 tempered steel and EN-GJS-700-2 cast iron. Wear 476:203737

6. Zhou WH, Tang JY, Shao W (2020) Study on surface generation mechanism and roughness distribution in gear profile grinding. Int J Mech Sci 187:105921

7. Sharmin I, Moon M, Talukder S, Alam M, Ahmed MF (2021) Impact of nozzle design on grinding temperature of hardened steel under MQL condition. Materialstoday: Proceedings 38:3232-3237

8. Cao Y, Yin JF, Ding WF, Xu JH (2021) Alumina abrasive wheel wear in ultrasonic vibration-assisted creep-feed grinding of Inconel 718 nickel-based superalloy. J Mater Process Technol 297:117241

9. Yang ZC, Zhu LD, Zhang GX, Ni CB, Lin B (2020) Review of ultrasonic vibration-assisted machining in advanced materials. Int J Mach Tools Manuf 156:103594

10. Cao Y, Zhu YJ, Ding WF, Qiu YT, Wang LF, Xu JH (2021) Vibration coupling effects and machining behavior of ultrasonic vibration plate device for creep-feed grinding of Inconel 718 nickel-based superalloy. Chin J Aeronaut 35:332-345

11. Dai CW, Yin Z, Wang P (2021) Analysis on ground surface in ultrasonic face grinding of silicon carbide (SiC) ceramic with minor vibration amplitude. Ceram Int 47:21959-21968

12. Zhang MH, Pang ZX, Jia YX, Shan CW (2021) Understanding the machining characteristic of plain weave ceramic matrix composite in ultrasonic-assisted grinding. Ceram Int 48:5557-5573

13. Rowe WB, Jin T (2001) Temperatures in high efficiency deep grinding (HEDG). CIRP AnnalsManufacturing Technology 50:205-208

14. Miao Q, Li HN, Ding WF (2020) On the temperature field in the creep feed grinding of turbine blade root: Simulation and experiments. Int J Heat Mass Transf 147:118957-118957

15. Rowe WB, Morgan MN, Black SCE (1996) A simplified approach to control of thermal damage in grinding. CIRP Annals - Manufacturing 45:299-302

16. Rowe WB (2017) Temperatures in Grinding - A Review. J Manuf Sci Eng 139:12

17. Malkin S, Guo C (2007) Thermal analysis of grinding. CIRP Annals - Manufacturing Technology 56:760-782

18. Singh V, Rao PV, Ghosh S (2012) Development of specific grinding energy model. Int J Mach Tools Manuf 60:1-13

19. Jaeger J, Carslaw H (1942) Moving sources of heat and the temperature of sliding contacts. New South Wales 76:202 
20. Rowe WB (2001) Thermal analysis of high efficiency deep grinding. Int J Mach Tools Manuf 41:1-19

21. Lavisse B, Lefebure A, Torrance AA (2018) The effects of the flow rate and speed of lubricoolant jets on heat transfer in the contact zone when grinding a nitrided steel. J Manuf Process 35:233-243

22. Chen J, Shi DQ, Miao GL, Yang XG (2017) Effect of maximum temperature on the thermal fatigue behavior of superalloy GH536. Appl Mech Mater 853:28-32

23. Qian N, Ding WF, Zhu YJ (2018) Comparative investigation on grindability of K4125 and Inconel 718 nickel-based superalloys. Int J Adv Manuf Technol 97:1649-1661

24. Wu BF, Zhao B, Ding WF (2021) Investigation of the wear characteristics of microcrystal alumina abrasive wheels during the ultrasonic vibration-assisted grinding of PTMCs. Wear 477:203844

25. Chen JB, Fang QH, Wang CC (2016) Theoretical study on brittle-ductile transition behavior in elliptical ultrasonic assisted grinding of hard brittle materials. Precis Eng 46:104-117

26. Pahlitzsch G, Helmerdig H (1943) Determination and significance of chip thickness in grinding. Workshop Technol 12:397-401

27. Zuo DW, Matsuo T (2001) Significance of grinding temperature in metal removal. Key Eng Mater 257:57-60

28. Ramesh K, Huang H, Yin L (2004) Analytical and experimental investigation of coolant velocity in high speed grinding. Int J Mach Tools Manuf 44:1069-1076

29. Winter M, Madanchi N, Herrmann C (2016) Comparative thermal analysis of cutting fluids in pendular surface grinding. Int J Adv Manuf Technol 87:1751-1763

30. Huang WT, Liu WS, Wu DH (2016) Investigations into lubrication in grinding processes using MWCNTs nanofluids with ultrasonic-assisted dispersion. J Clean Prod 137:1553-1559

31. Korpong V, Jirachai M, Teerapat $T$ (2021) Characterization of heat transfer and friction loss of water turbulent flow in a narrow rectangular duct under $25-40 \mathrm{kHz}$ ultrasonic waves. Ultrasonics 114:106366

32. Legay M, Gondrexon N, Person SL (2012) Enhancement of heat transfer by ultrasound: review and recent advances. Int J Chem Eng 43:102221

33. Zhang FL, Huang GW, Liu JM, Du ZJ, Wu SX, Wang CY (2021) Grinding performance and wear of metal bond super-abrasive tools in grinding of Zr-based bulk metallic glass. Int J Refract Met Hard Mater 97:105501

34. Bhaduri D, Soo SL, Aspinwall DK (2017) Ultrasonic assisted creep feed grinding of gamma titanium aluminide using conventional and superabrasive wheels. CIRP Annals - Manufacturing Technology 66:341-344

\section{Figures}



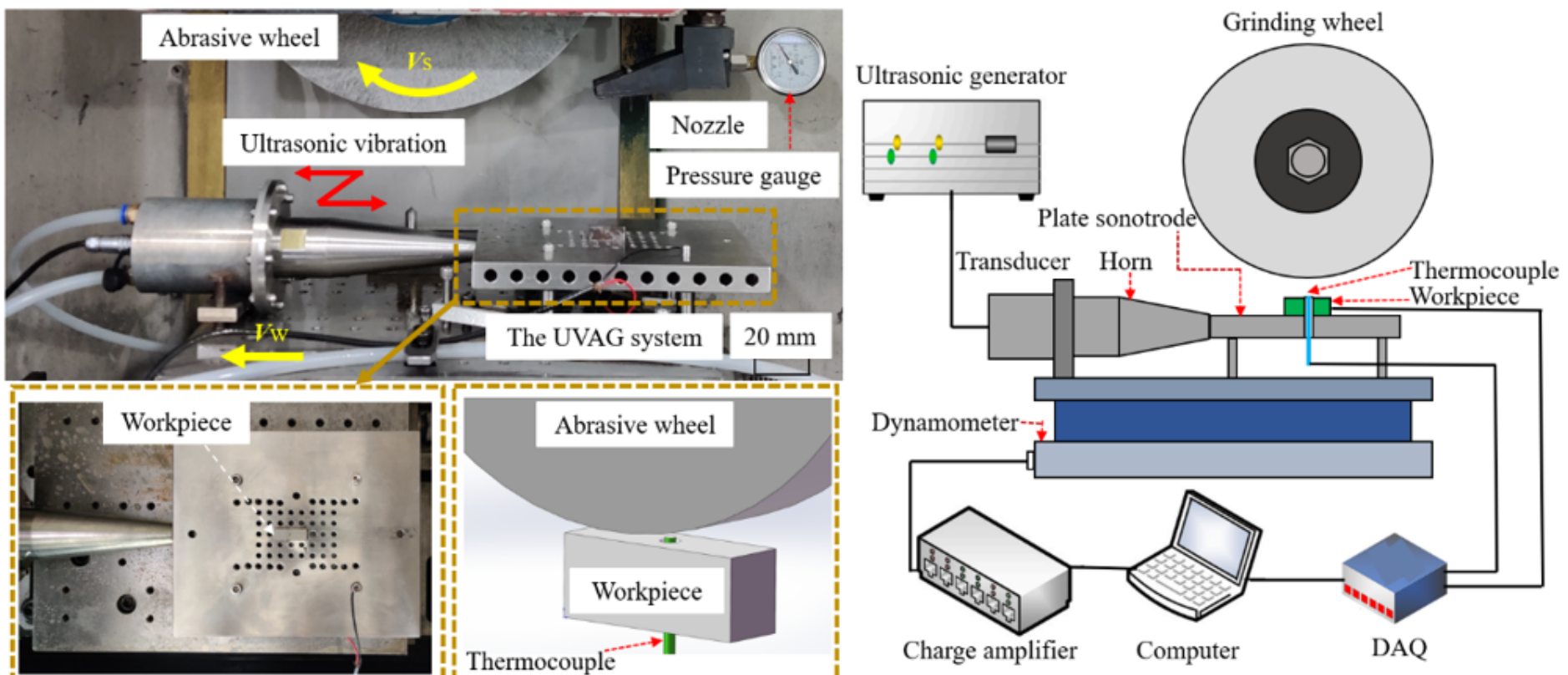

Figure 1

Schematic diagram of experimental setup and grinding equipment. 


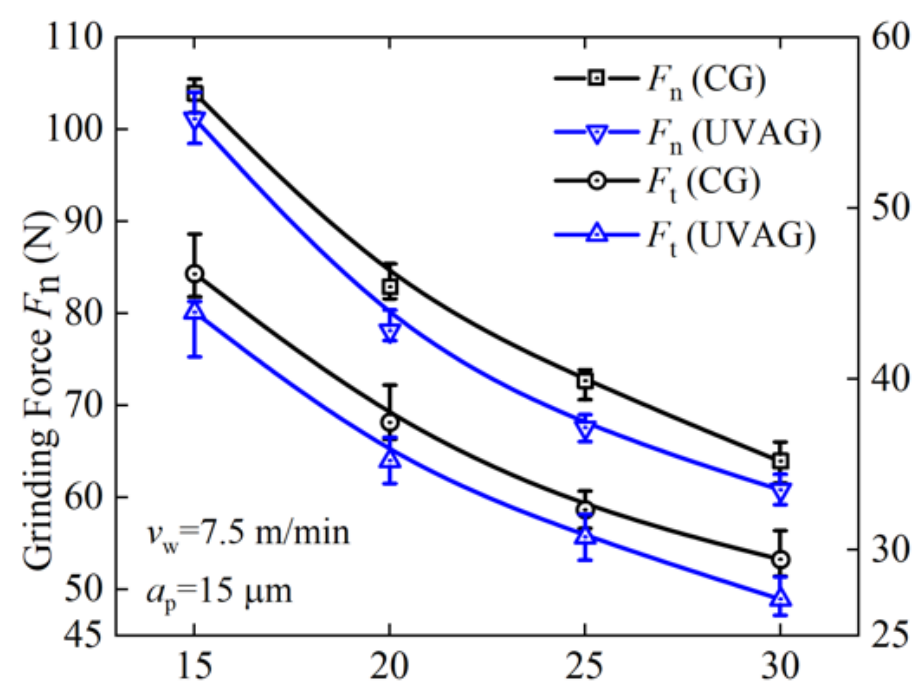

(a) Grinding speed $v_{\mathrm{s}}(\mathrm{m} / \mathrm{s})$

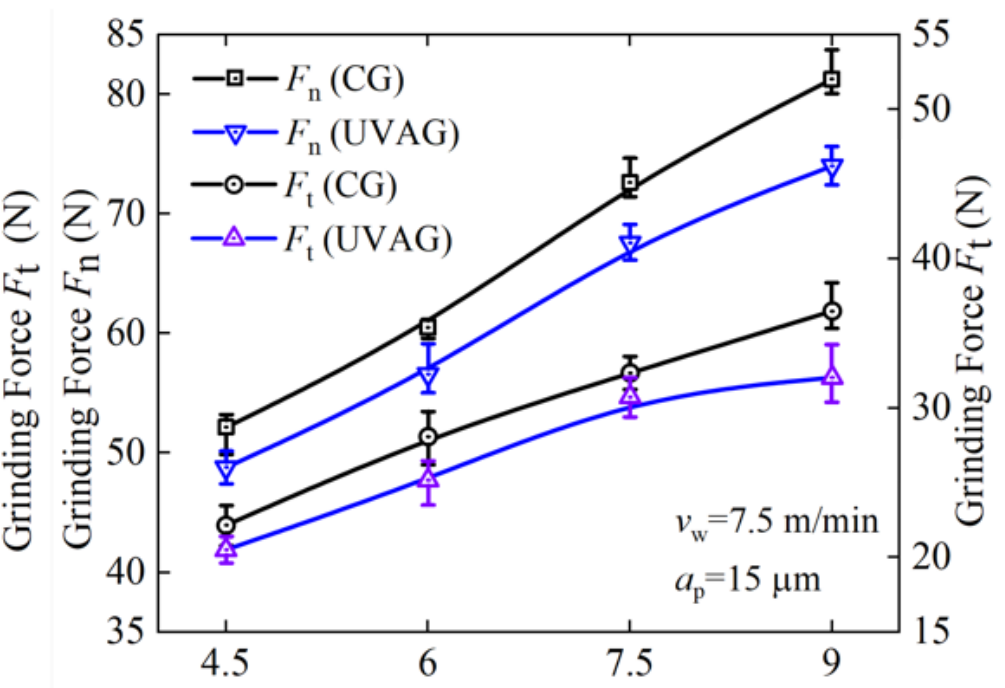

(b) Workpiece speed $v_{\mathrm{w}}(\mathrm{m} / \mathrm{min})$

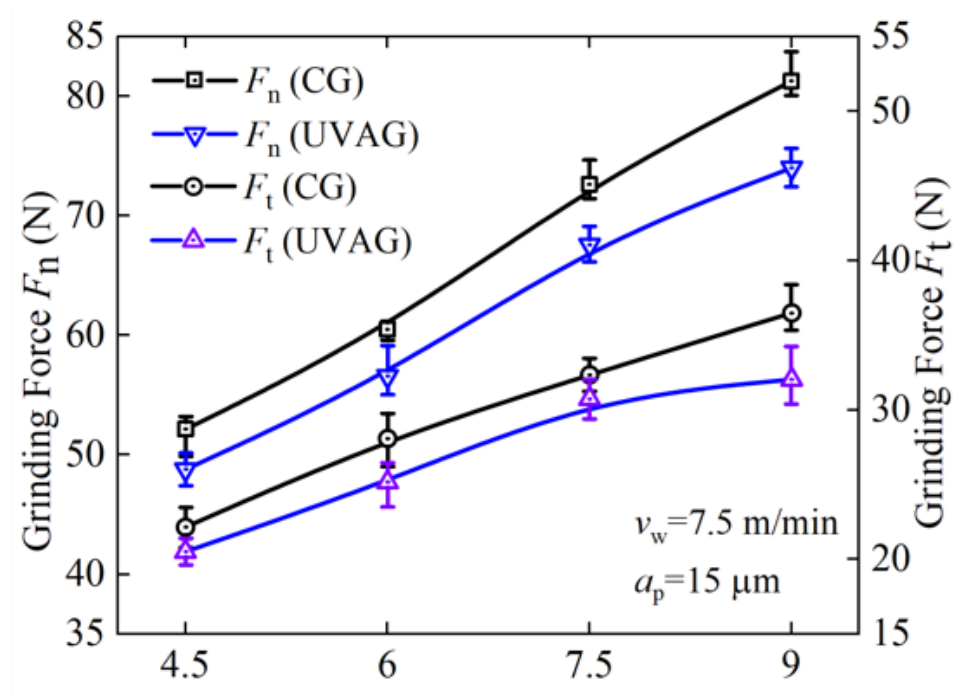

(b) Workpiece speed $v_{\mathrm{w}}(\mathrm{m} / \mathrm{min})$

Figure 2

Effects of grinding parameters on grinding forces during CG and UVAG processes. 

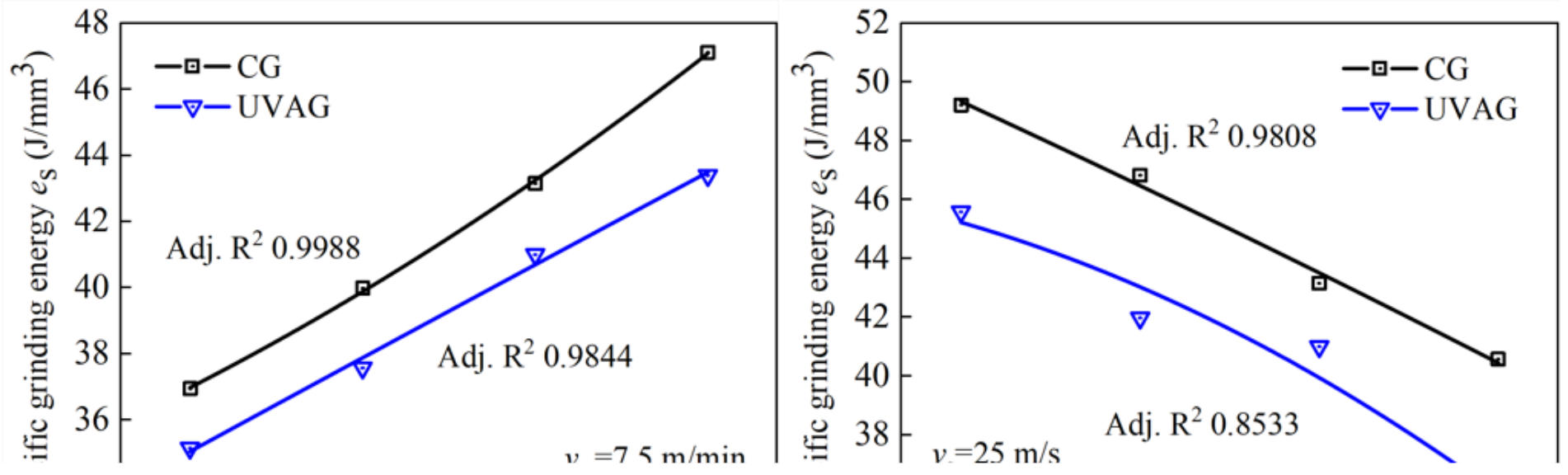

Figure 3

Effects of grinding parameters and maximum undeformed chip thickness on the specific grinding energy. 


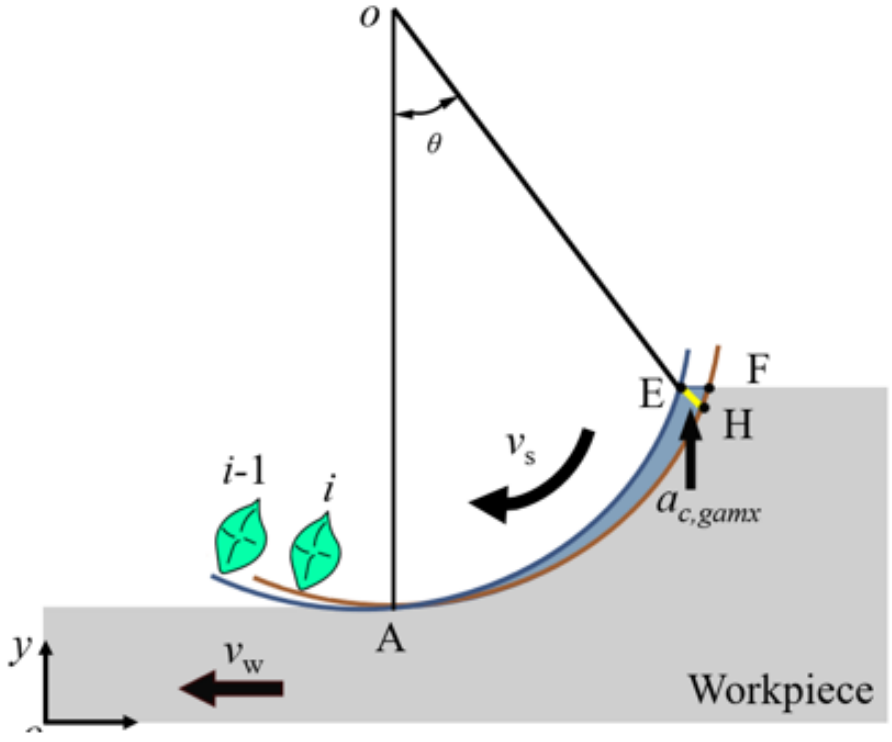

(a) CG method

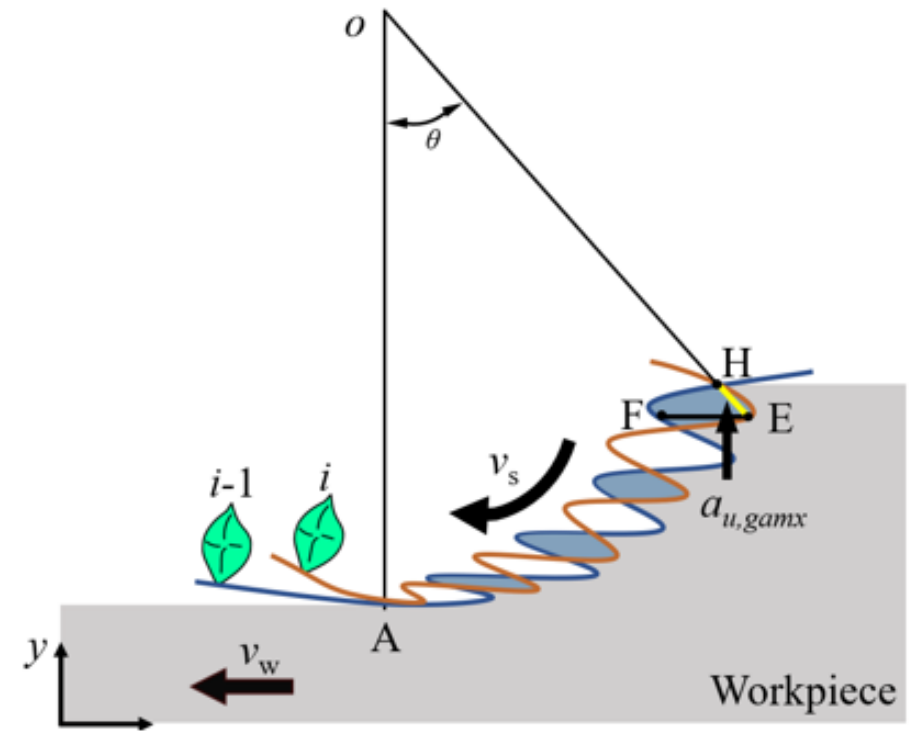

(b) UVAG method

\section{Figure 4}

Schematic diagram of chip formation and maximum undeformed cutting thickness for both grinding methods.

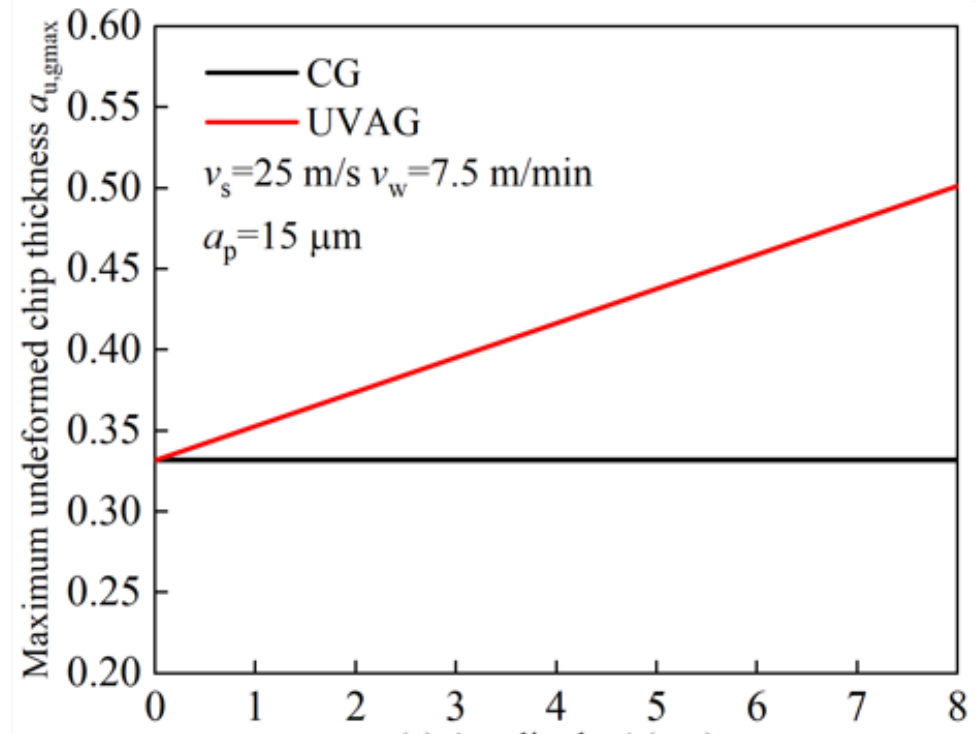

(a) Amplitude $A(\mu \mathrm{m})$

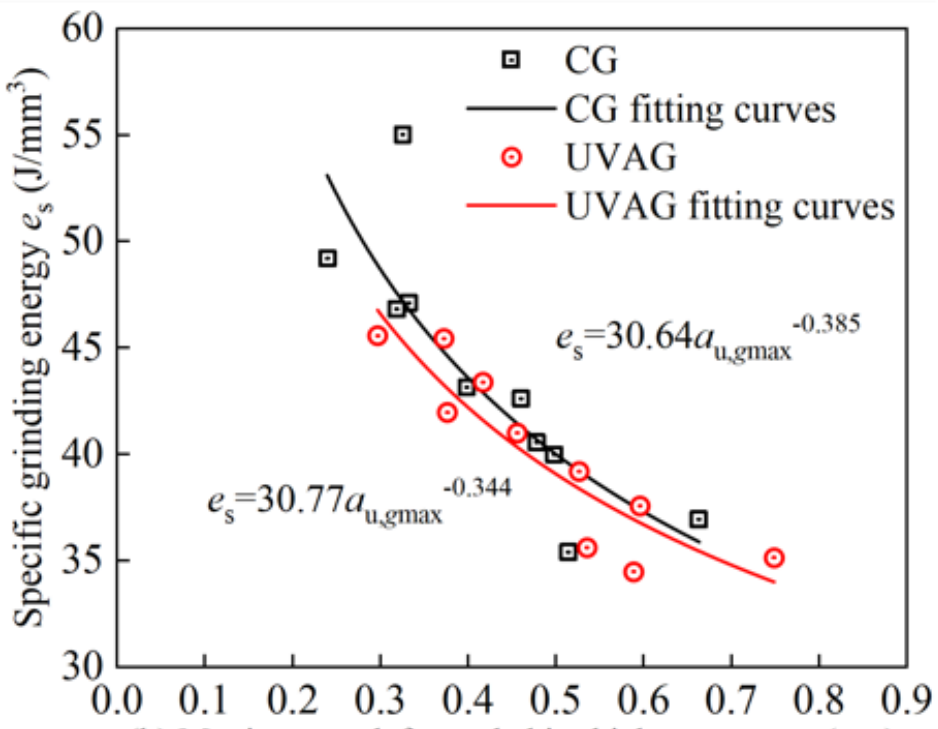

(b) Maximun undeformed chip thickness $a_{u, g \max }(\mu \mathrm{m})$

\section{Figure 5}

Plotted curves between the $a_{\mathrm{u}, g m a x}$ and amplitude as well as specific grinding energy. 


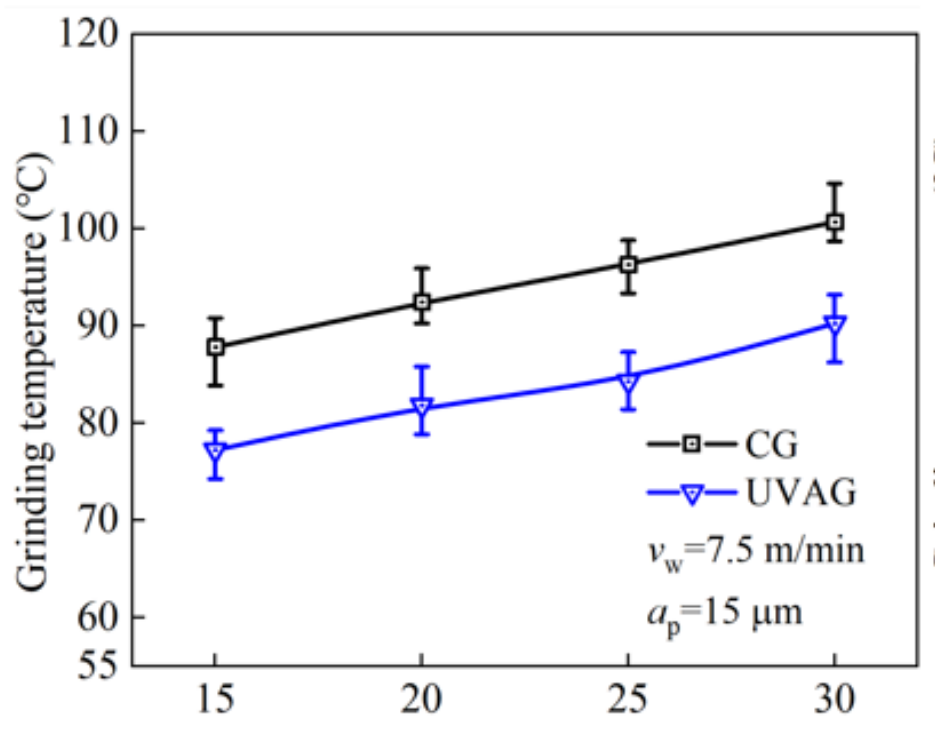

(a) Grinding speed $v_{\mathrm{s}}(\mathrm{m} / \mathrm{s})$

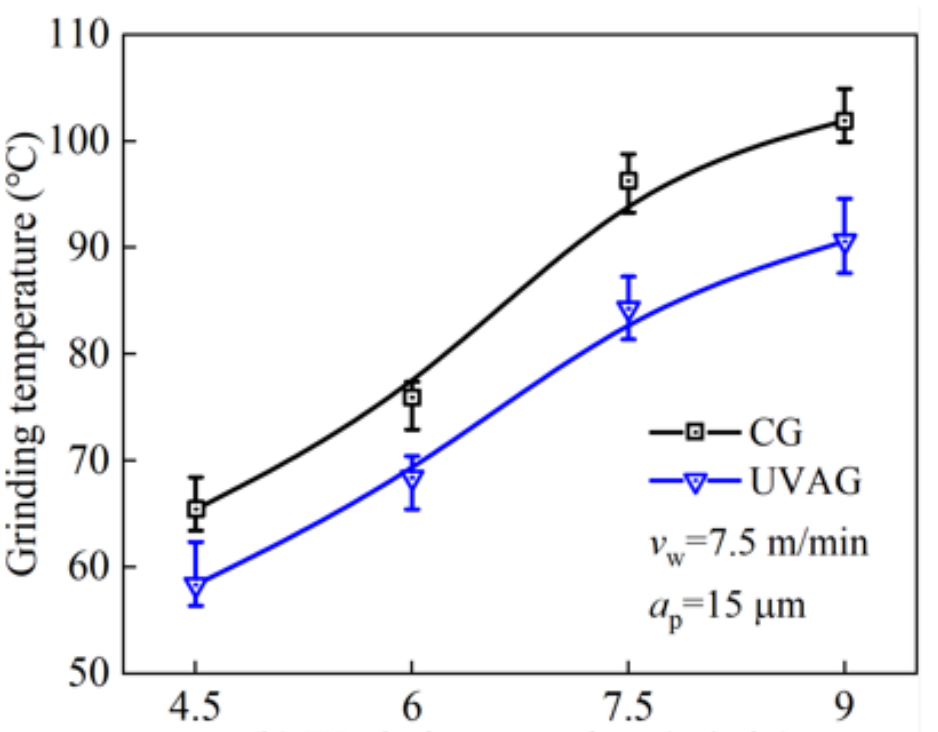

(b) Workpiece speed $v_{\mathrm{w}}(\mathrm{m} / \mathrm{min})$

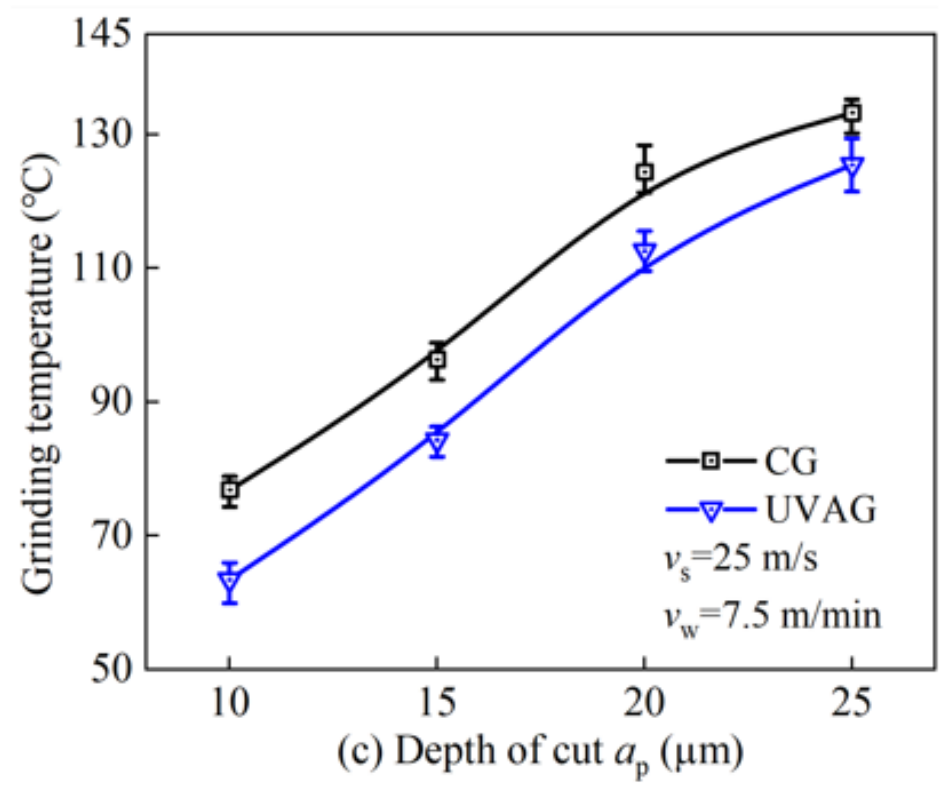

Figure 6

Grinding temperature versus different grinding parameters. 

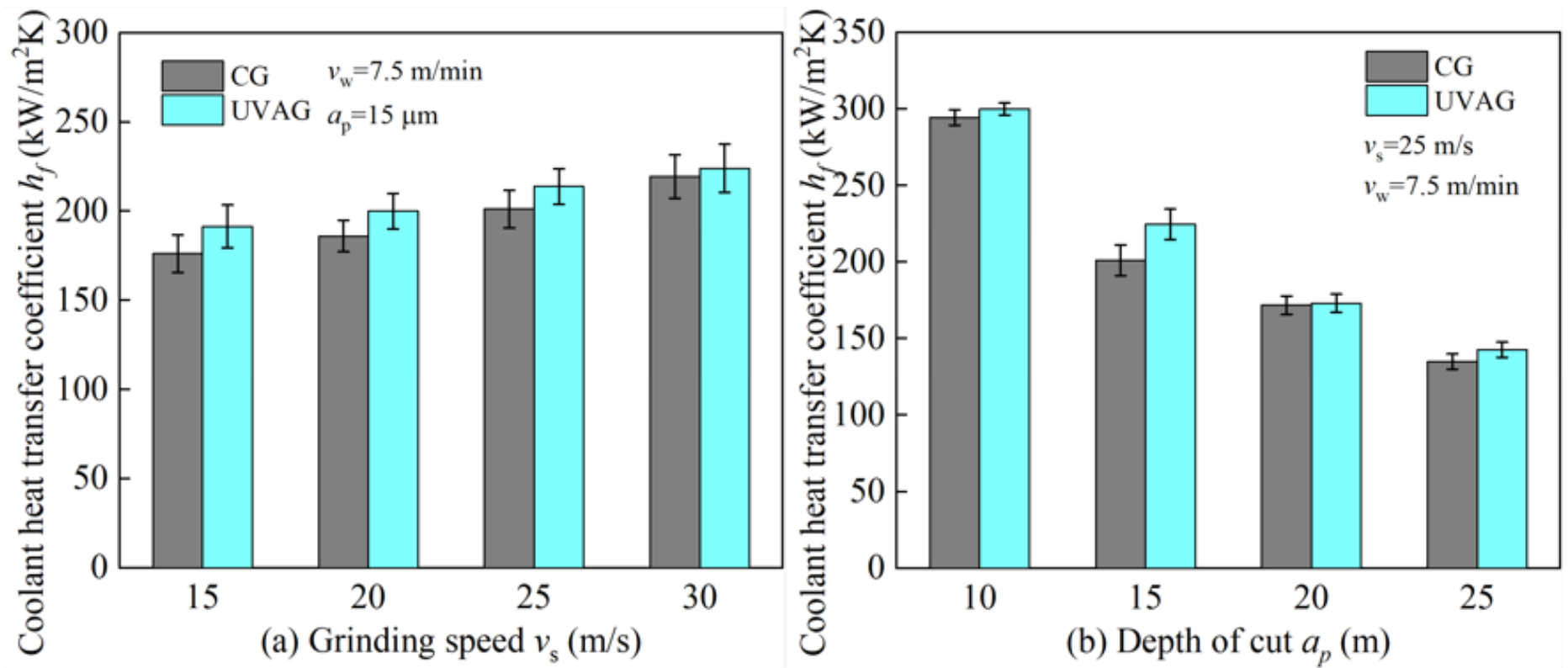

\section{Figure 7}

Coolant heat transfer coefficient versus the grinding speed and depth of cut.

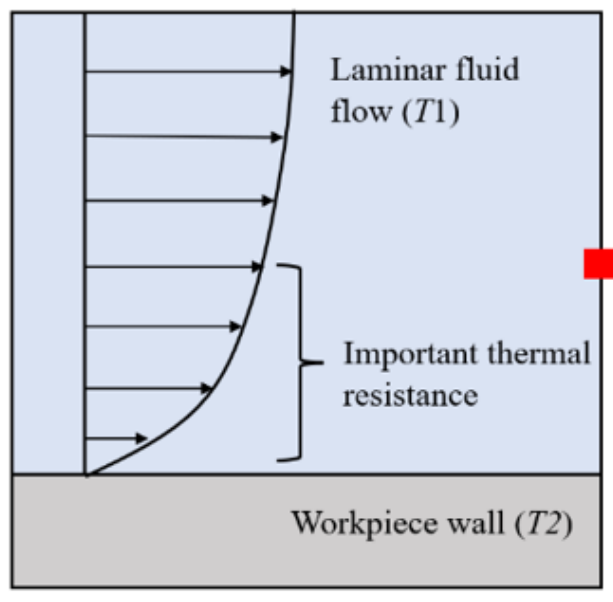

(a) Typical heat boundary layer

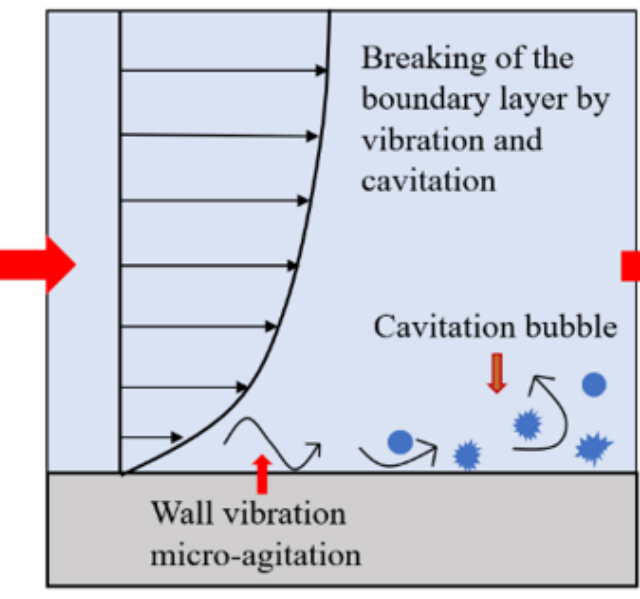

(b) Micro-agitation and cavitation

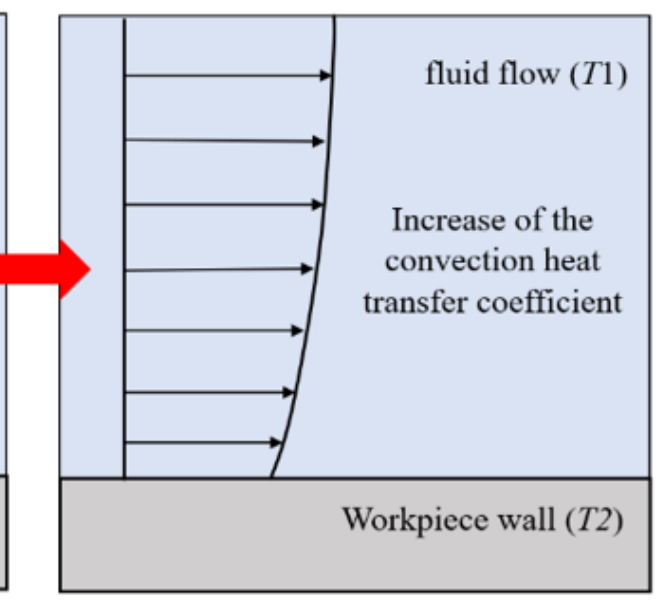

(c) Modified heat boundary layer profile

\section{Figure 8}

Diagram of the heat transfer enhancement mechanism by employing ultrasonic vibrations. 


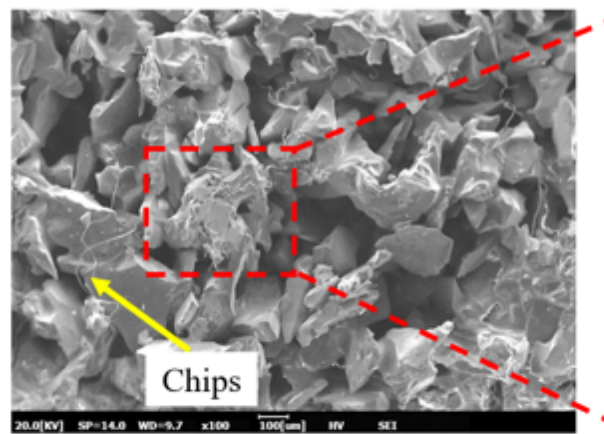

(a) CG whole image

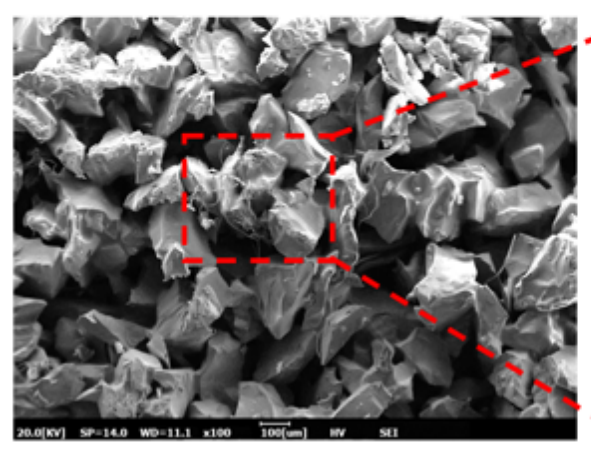

(a) UVAG whole image

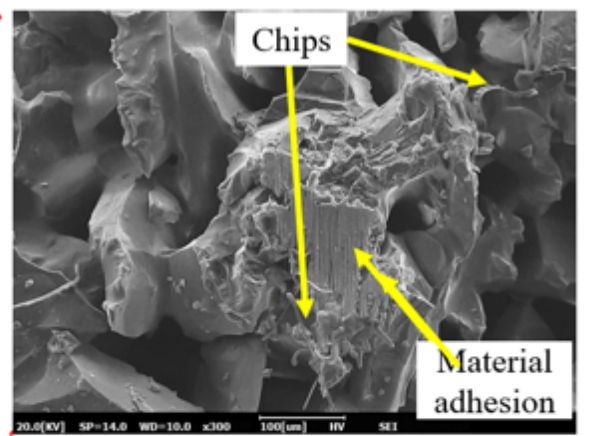

(b) CG regional image

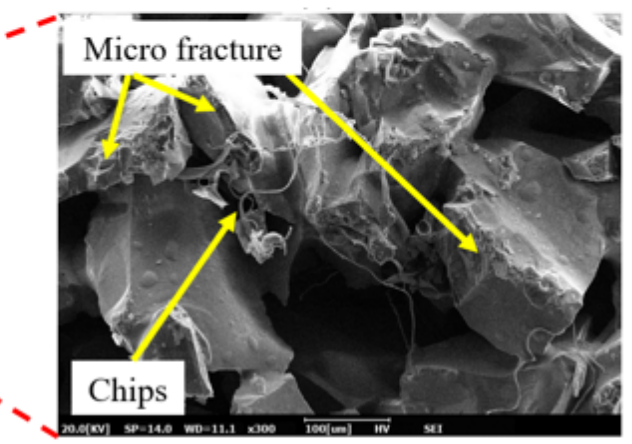

(b) UVAG regional image

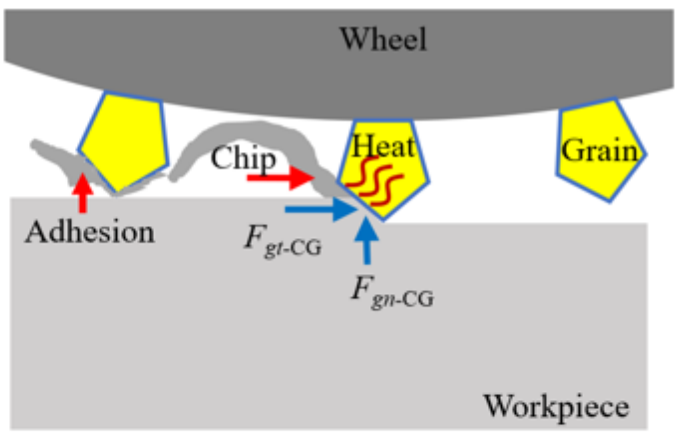

(c) Schematic of CG

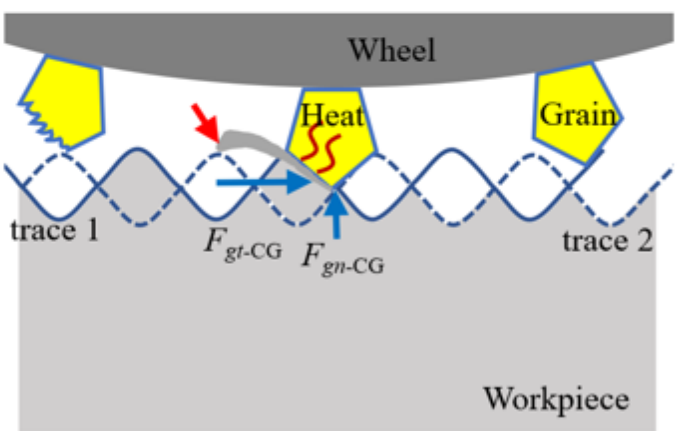

(c) Schematic of UVAG

\section{Figure 9}

SEM microstructures and schematic image of wheels surface under CG $(a, b, c)$ and UVAG (d, e, f) processes $\left(v_{\mathrm{s}}=25 \mathrm{~m} / \mathrm{s}, v_{\mathrm{w}}=7.5 \mathrm{~m} / \mathrm{min}, a_{\mathrm{p}}=25 \mu \mathrm{m}\right)$. 

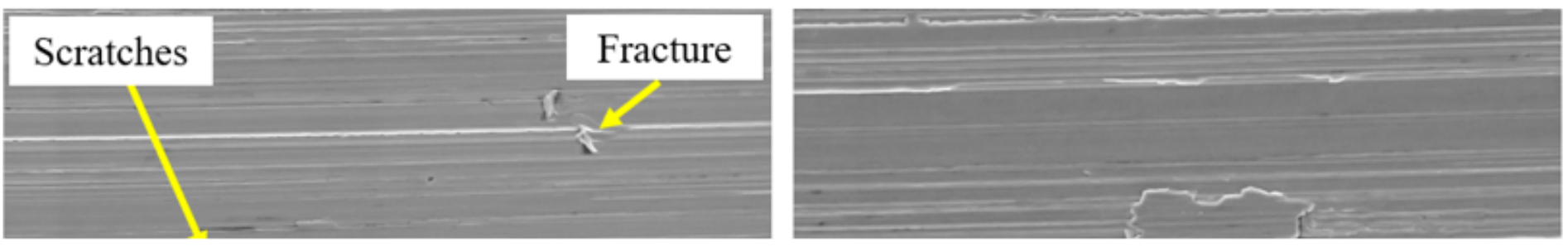

Figure 10

Ground surface morphologies after CG $(\mathrm{a}, \mathrm{b})$ and UVAG $(\mathrm{c}, \mathrm{d})$ processes $\left(v_{\mathrm{s}}=25 \mathrm{~m} / \mathrm{s}, v_{\mathrm{w}}=7.5 \mathrm{~m} / \mathrm{min}, a_{\mathrm{p}}=25\right.$ $\mu \mathrm{m})$. 